\title{
Polymerase-Functionalized Hierarchical Mesoporous Titania Thin Films: Towards a Nanoreactor Platform for DNA Amplification**
}

\author{
Martín G. Bellino, * Ivanna Tropper, Hebe Duran, Alberto E. Regazzoni, and \\ Galo J. A. A. Soler-Illia*
}

Nucleic acids are essential in life, as they control the functioning of the cells and carry the genetic information. DNA manipulation has become one of the most active research areas of current science. As a consequence, the development of advanced platforms able to interact with DNA is blooming. ${ }^{[1]}$ Integration of novel nanomaterials with advanced molecular biology techniques constitutes one of the main targets of nanobiotechnology. Here we report that polymerase-containing titania thin films of appropriate hierarchical nanoporous architecture are capable of performing DNA amplification.

DNA -polymerases are large-size enzymes involved in DNA replication that present functional and structural similarities. These enzymes read the nucleotide sequences of DNA templates to synthesize daughter copies of the original DNA molecules. ${ }^{[2]}$ The polymerase chain reaction (PCR) is the best-known and most successful methodology for amplification of nucleic acids, that is, for producing an unlimited number of replicas of any fragment of DNA. ${ }^{[3]} \mathrm{PCR}$, which opened up the capability of analyzing minute amounts of DNA or RNA, has a great impact in genetics, diagnostics, and forensics, and has become an indispensable technique in medicine, molecular biology, and biotechnology. The method consists of several

[*] Dr. M. G. Bellino, Prof. A. E. Regazzoni, Prof. G. J. A. A. Soler-Illia Gerencia Química, Comisión Nacional de Energía Atómica Av. Gral. Paz 1499, San Martín, B1650KNA (Argentina) E-mail: mbellino@cnea.gov.ar; gsoler@cnea.gov.ar

Prof. A. E. Regazzoni

Instituto Jorge A. Sabato

Universidad Nacional de San Martín

Av. Gral. Paz 1499, San Martín, B1650KNA (Argentina)

I. Tropper, Prof. H. Duran

Departamento de Radiobiología

Comisión Nacional de Energía Atómica

Av. Gral. Paz 1499, San Martín, B1650KNA (Argentina)

[**] Thanks are due to ANPCyT (PICT-34518, PICT-00335, and PAE37063/PME-00038) and to LNLS for travel support (projects D10A-XRD2 8260/08 and D11A-SAXS1-8249/08). I.T. acknowledges a fellowship from UNSAM, of which H.D. is a member. A.E.R., H.D., M.G.B., and G.J.A.A.S.-I. are members of CONICET.

몽 Supporting Information is available on the WWW under http:// www.small-journal.com or from the author.

DOI: $10.1002 / \mathrm{smll} .201000066$ heating-cooling cycles, in which DNA melting and enzymatic replication take place in the liquid phase.

The development of novel integrated devices for DNA manipulation requires the immobilization of any of the PCR components. Efforts in this direction address the attachment of primers to solid support surfaces and ensuing $\mathrm{PCR}^{[4]}$ and the anchorage of DNA for real-time detection. ${ }^{[5]}$ Bioactive platforms able to amplify free DNA strands have not yet been achieved. DNA amplification from biofunctional nanoreactors is perhaps the most difficult challenge faced by nanotechnology, since it shall certainly provide a new generation of scaffolds that will open a spectrum of advanced biotechnological applications. This Communication shows that this ambitious goal is close to realization.

Mesoporous particulate supports, with pore sizes ranging between 2 and $50 \mathrm{~nm}$, are attractive host matrices for entrapping enzymes. ${ }^{[6]}$ Despite most of them being able to accommodate large DNA molecules, ${ }^{[7]}$ no attempt of processing nucleic acids with enzyme-loaded mesoporous materials has yet been reported. Mesoporous thin films are particularly interesting because they are amenable to integration in devices that display properties derived from pore architecture and pore functionalization. ${ }^{[8]}$ Metal oxide-based mesoporous thin films with tuneable pore structure and uniform pore-size distribution are easily produced by sol-gel-evaporation-induced selfassembly procedures. ${ }^{[9]}$ Typically, pore sizes range within 2$10 \mathrm{~nm}$, depending on the amphiphilic template. Naturally, pore sizes and interpore necks must be adequately tailored to accommodate large bio-macromolecules, such as polymerase. ${ }^{[6 \mathrm{~b}]}$ Many active polymerases are housed in the cell nucleus in nanostructured clusters, ${ }^{[10]}$ thus it is conceivable that large-pore mesoporous films with wide interpore necks could provide an appropriate environment to grant biological activity. Recently, it has been shown that titania thin films with tuned hierarchical pore-size distributions and pores ranging between 10 and $100 \mathrm{~nm}$ can indeed be manufactured. ${ }^{[11]}$ Titania films, in addition, are biocompatible and stable under most physiological conditions. ${ }^{[12]}$ Enzyme functionalization of these films might therefore furnish substrates that may mimic complex biological membranes. As proof of concept, this Communication reports the PCR amplification of DNA from functional mesoporous nanostructures, and illustrates the dramatic influence of pore-size hierarchy. 


\section{communications}

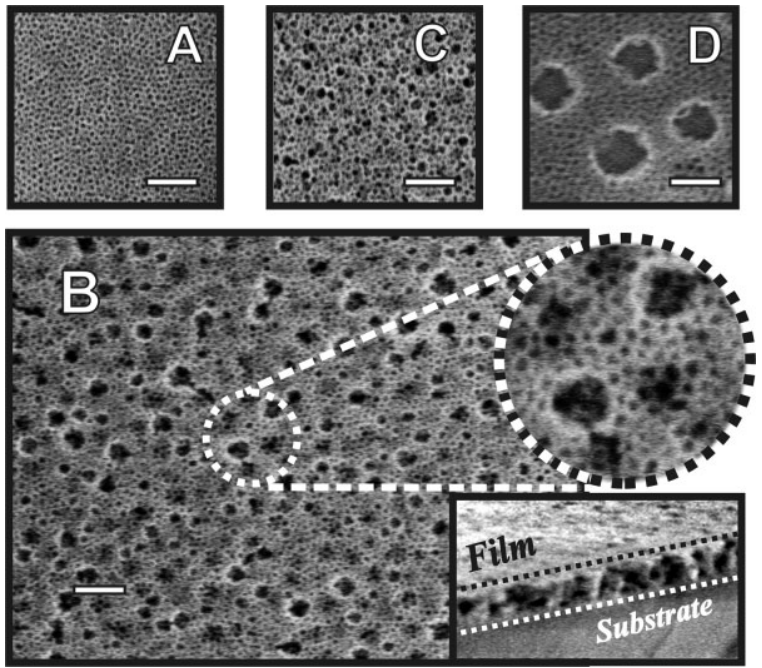

Figure 1. FE-SEM images of the various titania film supports tested in this study: F9 (A), F13/38 (B), F20 (C), and F15/95 (D); scale bar $=100 \mathrm{~nm}$. The inset in (B) depicts a cross-section view of film F13/38. See Experimental Section for synthesis conditions.

Supported mesoporous titania thin films were produced following the procedure reported by Malfatti et al. ${ }^{[11]}$ by adjusting carefully the relative proportions of the precursor $\left(\mathrm{TiCl}_{4}\right.$ ), water, template (Pluronics F127), co-template (PPG), solvent (butanol), and co-solvent (THF) in the sols (see Experimental Section for details). Figure 1 shows the nanoporous structure of the thus-prepared titania films. Depending on the initial sol composition, the transparent and crack-free films exhibit uniform (Figure 1A and C) and hierarchical (Figure 1B and D) pore-size distributions. These films shall hereafter be labeled F9 and F20, and F13/38 and F15/ 95, the tags denoting the size of their pores (Table 1; see also Supporting Information, Figures S1 and S2). Importantly, the larger mesopores of film F13/38 are interconnected and evenly distributed along the whole film thickness (see inset in Figure 1B). Conversely, the 95-nm macropores of film F15/ 95 are actually pinholes; note that film thickness ranges between 50 and $80 \mathrm{~nm}$. The textural characteristics of these films are summarized in Table 1.

To achieve film biofunctionalization, Taq polymerase was immobilized by immersing millimeter-sized pieces into

Table 1. Composition of the starting sols and textural characteristics of the resulting mesoporous films.

\begin{tabular}{|c|c|c|c|c|}
\hline & F9 & $\mathrm{F} 13 / 38$ & $\mathrm{~F} 20$ & $\mathrm{~F} 15 / 95$ \\
\hline$P$ & 0 & $6.2 \times 10^{-3}$ & $6.2 \times 10^{-3}$ & $1.2 \times 10^{-2}$ \\
\hline$V_{\mathrm{THF}}(\%)$ & 0 & 0 & 17 & 17 \\
\hline Mean pore size $[\mathrm{nm}]^{[\mathrm{a}]}$ & 8.6 & $13 \& 38$ & 20 & $15 \& 95^{[b]}$ \\
\hline Neck size $[\mathrm{mm}]^{[\mathrm{a}]}$ & 4.8 & $6.3^{[c]}$ & 6.9 & $6.6^{[c]}$ \\
\hline Film porosity [\%] ${ }^{[\mathrm{a}]}$ & 39 & 47 & 37 & 41 \\
\hline Film thickness $[\mathrm{nm}]^{[\mathrm{a}]}$ & 67 & 78 & 51 & 58 \\
\hline
\end{tabular}

[a] Determined by FE-SEM images and environmental ellipsometric porosimetry (EEP); see Supporting Information for details. [b] 95-nm macropores are undetected by EEP. [c] Note that only the smaller necks are made evident by water vapor desorption. ${ }^{[13]}$

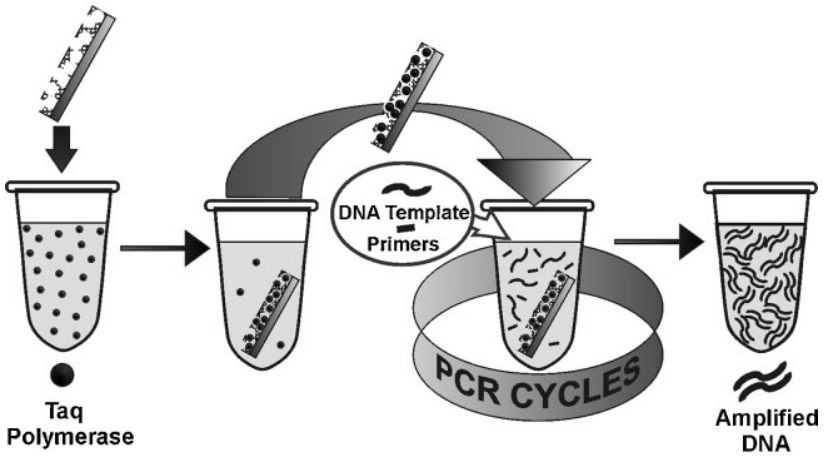

Scheme 1. Schematic representation of the experimental approach followed to accomplish DNA amplification by Taq polymerasefunctionalized hierarchical mesoporous titania films.

buffered solution containing 2.5 units of the enzyme; afterwards, the films were rinsed thoroughly with water to remove any excess polymerase. The capability of these pre-incubated films to amplify DNA was then tested following a conventional PCR protocol but using the pre-incubated films instead of free Taq polymerase (see Scheme 1). Briefly, tests were carried out by placing the pre-incubated film pieces in buffered solution containing the four nucleotides, the DNA strand template, and T7 and SP6 universal primers, and subjecting the systems to a typical PCR thermal cycling (see Experimental Section). The DNA template was a synthetic, linear, 100-base single strand, which corresponds to a fragment from the polylinker region in the pcDNA3 plasmid.

Of all the pre-incubated films, only film F13/38 was bioactive, as evident by lanes $\mathrm{A}$ to $\mathrm{D}$ in the upper frame of Figure 2, which shows that the 100-bp fragment was successfully amplified by film F13/38 solely (Figure 2, lane B); independent runs confirmed these observations, and showed that the activity of the biofunctionalized 13/38-nm-pore-size hierarchical film is reproducible. The activity of this film is slightly lower than that of 2.5 units of free DNA polymerase (cf. Figure 2 top, lane +, and SI Figure S3). The observed lower optical density of the stripe corresponding to the bioactive film with respect to the ordinary PCR run may be attributed to two different facts: not all of the enzyme has been adsorbed by the film during the preincubation step, and part of the adsorbed enzyme becomes inactive. Lane 5 in the lower frame of Figure 2 indicates that polymerase adsorption was not completed during film functionalization. Whether immobilization affects the activity of the entrapped enzyme is an open question. Nonetheless, this result demonstrates that a straightforward thin-film platform with the appropriate mesoporous architecture is able to amplify DNA with a performance that is of the same order of magnitude as that of the standard PCR.

The above results illustrate the effect of film mesopore architecture on their capacity to be functionalized. Such a notable effect can be traced back to the inability of films F9, F20, and F15/95 to host Taq polymerase. Gel electrophoresis analyses of the DNA products obtained from PCR of the supernatants recovered after films pre-incubation (Supporting Information, Figure S4) show that film F13/38 presents the largest and most significant polymerase uptake. Therefore, it can be concluded that the lack of bioactivity of films F9, F20, and 

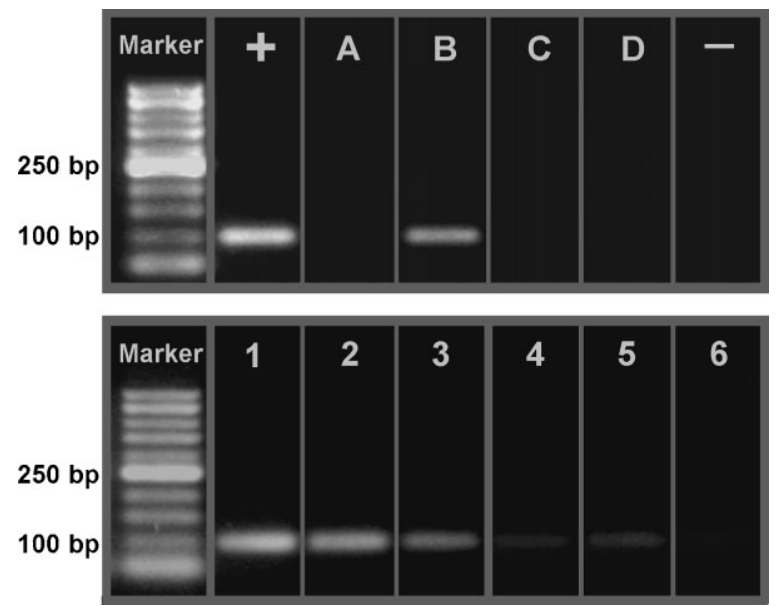

Figure 2. Upper frame: Gel electrophoresis analysis of DNA products from: +) liquid phase standard PCR run; A) film F9; B) film F13/38; C), film F20; D) film F15/95; -) negative control (i.e., absence of DNA template); all films were pre-incubated in Taq polymerase solutions. Lower frame: Gel electrophoresis analysis of DNA products from: $1-3$ ) successive PCR runs using the same polymerase-functionalized F13/38 film; 4) a waterrinsed pre-used F13/38 film subjected to PCR in the absence of DNA template; 5) recovered solution of the pre-incubation of film F13/38 subjected to PCR in the absence of added polymerase; 6 ) recovered buffer solution thermally cycled in contact with polymerase-functionalized film F13/38 subjected to PCR without added polymerase. Left lanes correspond to a 50 bp marker.

F15/95 is due to their inability to incorporate significantly the enzyme, and not to enzyme inactivation. Taq polymerase is a relatively large protein, composed of three domains, presenting an elongated shape $13.2 \mathrm{~nm}$ long and $\approx 6.5-7 \mathrm{~nm}$ in maximum diameter, ${ }^{[14]}$ with a reported gyration diameter in solution of $\approx 9.2 \mathrm{~nm} \cdot{ }^{[15]}$ In principle, the enzyme volume is too large for a 9-nm pore array. Thus, no significant loading of Taq polymerase in film F9 is possible, and enzymatic activity is not detected. Larger pores $(13-20 \mathrm{~nm})$ should be able to accommodate the enzyme, but the rather narrow necks between these mesopores (Table 1) prevent polymerase incorporation; ${ }^{[6 \mathrm{~b}]}$ this is the case of film F20. The inactivity of the hierarchical film F15/95 can be traced back to the pinhole characteristic of the 95-nm macropores, which are ten times larger than the enzyme. From a nanoscopic point of view, the walls of these craters are indistinguishable from the surface of a non-hierarchical 15-nmpore-size film, with 6.6-nm necks, a similar situation to that of film F20. Clearly, high pore volume and/or film hierarchy are not sufficient for bio-functionalization, and appropriate tailoring of pore architecture is therefore essential.

Film F13/38 presents an optimum situation: a significantly higher porosity and two efficiently interconnected pore populations. Environmental ellipsometric porosimetry was used to measure water adsorption-desorption isotherms, from which pore volume and pore size distributions were derived (see Supporting Information for details). ${ }^{[16]}$ Measurements on bare and functionalized F13/38 films are presented in Figure 3. The enzyme-free film presents a high porous volume and a bimodal pore size distribution (see also Table 1). Importantly, film pre-incubation (in the polymerase solution) leads to a

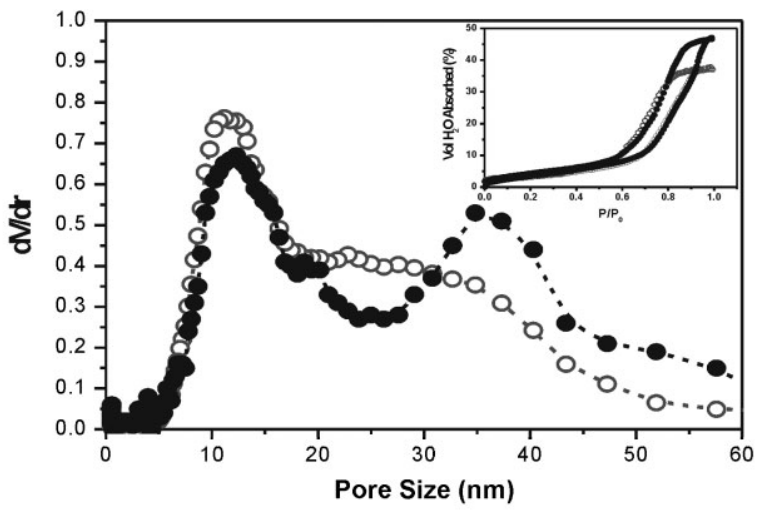

F9

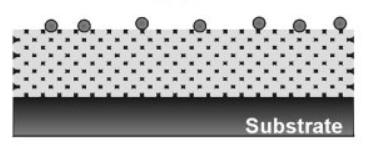

F20

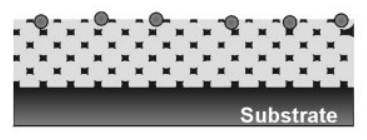

\section{$F 13 / 38$}

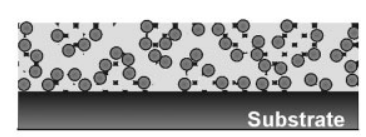

F15/95

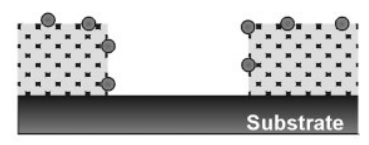

Taq Polymerase
Figure 3. Upper frame: Pore-size distributions of the bare film F13/38 (--•--) and of the polymerase-functionalized film F13/38(--O--). PSD was obtained by EEP from the adsorption branch of the water adsorptiondesorption isotherms (inset), at $T=298 \mathrm{~K}$. Lower frame: Schematic illustration of the putative enzyme localization in the different titania films used in this work.

marked decrease of the total pore volume, and to a significant reduction of the larger mesopore population, which becomes notably broader. The distribution of the smaller 13-nm mesopores, on the contrary, remains practically unaffected upon polymerase incorporation; this is due to the constraints imposed by the 6.3-nm necks of the latter mesopores. Such a significant change of the pore-size distribution indicates that the enzyme is only incorporated into the larger pores of the hierarchical F13/38 film. The 38-nm mesopores are interconnected through much wider necks (see the cross-section and top views of the film in the inset of Figure 1B). These mesopores act as cages for the Taq polymerase, where DNA amplification takes place. The smaller pores connect the larger ones and allow for the supply of reactants into the larger mesopores and for the outward diffusion of the replicated DNA product. Remarkably, the hierarchical nanoarchitecture of the F13/38 pore system makes bio-functionalization of the film possible, and allows PCR to occur. A simplified view of enzyme incorporation is presented in Figure 3.

To test the stability of the attachment of polymerase to the inner skeleton of film F13/38, the following experiments were performed: the enzyme-functionalized film was first cycled according to the PCR protocol in a buffered solution. This solution was then withdrawn, mixed with the PCR reactants (no 


\section{communications}

polymerase added), and subjected to further PCR thermal cycles. No DNA amplification was detected (Figure 2 bottom, lane 6), indicating that Taq polymerase remained firmly entrapped within the hierarchical mesoporous film during the PCR run. This resistance to desorption can be attributed to electrostatic and van der Waals interactions, and to the likely coordination of surface titanium ions by the carboxylate groups of the protein. ${ }^{[6 \mathrm{~b}, 17]}$ The stability of the anchoring of Taq polymerase during DNA replication was in addition confirmed by subjecting the bio-functionalized films to subsequent PCR runs (30 cycles each); for this purpose, the films were removed from the PCR tube after each run, rinsed thoroughly with water, and re-immersed in a fresh PCR cocktail. Lanes 1 to 3 in the lower frame of Figure 2 show that the polymerase-functionalized films remained fairly active, even after three successive PCR runs. Interestingly, the performance of these films did not deteriorate significantly; the apparent decrease of the optical density of the stripes (cf. Supporting Information, Figure S3) may reveal a slight loss of activity, which could be attributed to the damage of Taq polymerase caused by prolonged exposure to the high temperature of the denaturation step of the PCR cycles.

The above finding also indicates that the present biofunctionalized films can be reused to produce additional DNA amplification, hence incrementing the yield per enzyme of the replicated DNA strand, significantly. Film re-utilization, however, must be restricted to the amplification of the original DNA strand, otherwise cross-contamination may occur. In fact, thorough water rinsing was insufficient to remove all of the remnant DNA product that remained adhered to the film after PCR (see lane 4 in the lower frame of Figure 2).

In summary, the present work demonstrates that a stable nanoreactor scaffold hosting Taq polymerase able to perform DNA amplification can indeed be constructed. It further shows that appropriate control of the film nanopore architecture is key to bio-functionalization. Such a particular structure is achieved by engineering pore sizes and interconnectivity. The simplicity of the procedure used to prepare these bio-functionalized nanostructured platforms able to perform PCR is noteworthy. The proposed methodology offers a novel approach to biofunctionalization for DNA amplification, which is compatible with the techniques and substrates that are used in the development of integrated devices for fast PCR, ${ }^{[18]}$ sensors, ${ }^{[19]}$ lab-on-chip microfluidic assemblies, ${ }^{[20]}$ as well as microarrays and bio-MEMs. Moreover, it opens a path to a new generation of hybrid nanostructured bioactive films with foreseeable applications in portable devices of use in molecular medicine, DNA sequencing, bioanalysis and emerging areas, such as nucleic acid nanotechnology ${ }^{[21]}$ and DNA computers. ${ }^{[22]}$

\section{Experimental Section}

Film synthesis: $\mathrm{TiCl}_{4}$ (99.9\%), triblock-copolymer Pluronics F127 $\left(\mathrm{PEO}_{106}-\mathrm{PPO}_{70}-\mathrm{PEO}_{106}\right)$, poly(propylene glycol) PPG $\left(\mathrm{PPO}_{68}\right.$, $M_{\mathrm{W}} \approx 4000$ ), butanol and tetrahydrofuran (THF) were purchased from Aldrich, and used as received. Titania films were produced by dip-coating at a withdrawal rate of $0.5 \mathrm{~mm} \mathrm{~s}^{-1}$. Prior to deposition, soda-lime glass slides ( $24 \mathrm{~mm}$ long, $24 \mathrm{~mm}$ wide, $0.13 \mathrm{~mm}$ thick) were washed thoroughly with dextran, and rinsed successively with water, ethanol, and acetone. The relative humidity (RH) during dip-coating was set at $20 \%$. After deposition, films were aged at $50 \% \mathrm{RH}$ for $24 \mathrm{~h}$, and then dried at 60 and $130^{\circ} \mathrm{C}$ for $24 \mathrm{~h}$ at each temperature. Finally, they were calcined in air at $350^{\circ} \mathrm{C}$ for $2 \mathrm{~h}$; the temperature ramp was $1^{\circ} \mathrm{C} \mathrm{min}^{-1}$. Molar ratios in the precursor sols were $\mathrm{TiCl}_{4}: \mathrm{BuOH}: \mathrm{H}_{2} \mathrm{O}: \mathrm{F} 127: \mathrm{PPG}=1: 40: 10: 4 \times 10^{-3}: P$, where $P=[\mathrm{PPG}] /[\mathrm{Ti}]$. The synthesis parameters for each film sample are listed in Table 1 , where $V_{\mathrm{THF}}$ is the volume of added THF relative to the final sol volume. The resulting films were characterized as described in the Supporting Information.

Enzyme immobilization: Protein immobilization was achieved by immersing millimeter-sized pieces of the thus-prepared nanoporous films (2.5- $\mathrm{mm}^{2}$ total geometrical area) in $40 \mu \mathrm{L}$ of a 2.5-unit Taq polymerase (Invitrogen) buffered solution (20 mM Tris$\mathrm{HCl}(\mathrm{pH} \mathrm{8.4);50} \mathrm{mm} \mathrm{KCl})$ for $60 \mathrm{~min}$ at $0{ }^{\circ} \mathrm{C}$. Then, the films were thoroughly rinsed with water.

PCR amplification: The 100-base single-stranded DNA (Integrated DNA Technologies) TAATACGACTCACTATAGGGA GACCCAAGCTTGGTACCGAGCTCGGATCCACTAGTAACGG CCGCCAGTGTGCTGGAATTCCTATAGTGTCACCTAAATC was amplified using the T7 "TAATACG ACTCACTATAGGG" and SP6 "GATTTAGGTGACACTATAG" universal primers.

All PCR reactions were performed with the same PCR mixture, that is, $20 \mathrm{~mm}$ Tris- $\mathrm{HCl}(\mathrm{pH} 8.4), 50 \mathrm{~mm} \mathrm{KCl}, 1.0 \mathrm{~mm} \mathrm{MgCl} 2,0.2 \mathrm{~mm}$ of each deoxynucleotide triphosphate (dNTPs), $0.75 \mathrm{~mm}$ primers, and $100 \mathrm{fmoles}$ of template in a total solution volume of $50 \mu \mathrm{L}$. The PCR mix was then put in contact with $2.5 \mathrm{~mm}^{2}$ (geometrical area) of films pre-incubated in polymerase, and subjected to the following temperature protocol: i) $1 \mathrm{~min}$ at $94^{\circ} \mathrm{C}$ for denaturation; ii) 30 cycles each of $30 \mathrm{~s}$ at $94^{\circ} \mathrm{C}, 60 \mathrm{~s}$ at $50^{\circ} \mathrm{C}$, and $30 \mathrm{~s}$ at $72^{\circ} \mathrm{C}$; iii) $5 \mathrm{~min}$ at $72^{\circ} \mathrm{C}$. For positive control PCR experiments 2.5 units of Taq polymerase was added to the mix. DNA amplification was confirmed by gel electrophoresis; samples were run on $2 \%$ agarose gel in TAE buffer ( $40 \mathrm{~mm}$ Tris-acetate, $1 \mathrm{~mm}$ EDTA; $\mathrm{pH}$ 8.3) at $100 \mathrm{~V}$ for $45 \mathrm{~min}$. Products were visualized by staining with the fluorescent probe ethidium bromide. Negative control experiments, that is, without the DNA template, were also carried out.

\section{Keywords:}

DNA • hierarchical films - mesoporous thin films . nanobiotechnology

[1] a) M. Xu, D. Fujita, N. Hanagata, Small 2009, 5, 2638-2649; b) J. Eid, A. Fehr, J. Gray, K. Luong, J. Lyle, G. Otto, P. Peluso, D. Rank, P. Baybayan, B. Bettman, A. Bibillo, K. Bjornson, B. Chaudhuri, F. Christians, R. Cicero, S. Clark, R. Dalal, A. deWinter, J. Dixon, M. Foquet, A. Gaertner, P. Hardenbol, C. Heiner, K. Hester, D. Holden, G. Kearns, X. Kong, R. Kuse, Y. Lacroix, S. Lin, P. Lundquist, C. Ma, P. Marks, M. Maxham, D. Murphy, I. Park, T. Pham, M. Phillips, J. Roy, R. Sebra, G. Shen, J. Sorenson, A. Tomaney, K. Travers, M. Trulson, J. Vieceli, J. Wegener, D. Wu, A. Yang, D. Zaccarin, P. Zhao, F. Zhong, J. Korlach, S. Turner, Science 2009, 323, 133-138; c) J. Clarke, H. C. Wu, L. Jayasinghe, A. Patel, S. Reid, H. Bayley, Nat. Nanotechnol. 2009, 4, 265-270.

[2] a) B. Alberts, A. Johnson, J. Lewis, M. Raff, K. Roberts, P. Walter, Molecular Biology of the Cell, $4^{\text {th }}$ ed. Garland Science, New York 2002; b) T. A. Steitz, J. Biol. Chem. 1999, 274, 17395-17398. 
[3] K. B. Mullis, F. Ferre, R. A. Gibbs, The Polymerase Chain Reaction, Birkhauser, Boston 1994.

[4] a) C. Adessi, G. Matton, G. Ayala, G. Turcatti, J. J. Mermod, P. Mayer, E. Kawashima, Nucleic Acids Res. 2000, 28, E87; b) H. B. Shen, M. Hu, Y. B. Wang, H. Q. Zhou, Biophys. Chem. 2005, 115, 63-66.

[5] S. Sabella, G. Vecchio, R. Cingolani, R. Rinaldi, P. P. Pompa, Langmuir 2008, 24, 13266-13269.

[6] a) C.-H. Lee, T.-S. Lin, C.-Y. Mou, Nano Today, 2009, 4, 165-179; b) H. H. P. Yiu, P. A. Wright, J. Mater. Chem. 2005, 15, 3690-3700; c) M. Hartmann, Chem. Mater. 2005, 17, 4577-4593.

[7] a) F. Gao, P. Botella, A. Corma, J. Blesa, L. Dong, J. Phys. Chem. B 2009, 113, 1796-1804; b) S. M. Solberg, C. C. Landry, J. Phys. Chem. B 2006, 110, 15261-15268.

[8] a) S. Kataoka, A. Endo, M. Oyama, T. Ohmori, Appl. Catal A: Gen. 2009, 359, 108-112; b) M. G. Bellino, A. E. Regazzoni, G. J. A. A. Soler-Illia, Appl. Mater. Interfaces 2009, 2, 360-365.

[9] a) G. J. A. A. Soler-Illia, C. Sanchez, B. Lebeau, J. Patarin, Chem. Rev. 2002, 102, 4093-4138; b) G. J. A. A. Soler-Illia, E. L. Crepaldi, D. Grosso, C. Sanchez, Curr. Opin. Colloid Interface Sci. 2003, 8, 109-126; c) G. J. A. A. Soler-Illia, P. Innocenzi, Chem. Eur. J. 2006, 12, 4478-4494; d) C. Sanchez, C. Boissière, D. Grosso, C. Laberty, L. Nicole, Chem. Mater. 2008, 20, 682-737; e) P. Innocenzi, L. Malfatti, T. Kidchob, P. Falcaro, Chem. Mater. 2009, 21, $2555-2564$

[10] a) F. J. Iborra, A. Pombo, J. McManus, D. A. Jackson, P. R. Cook, Exp. Cell Res. 1996, 229, 167-173; b) S. Martin, A. Pombo, Chromosome Res. 2003, 11, 461-470.

[11] L. Malfatti, M. G. Bellino, P. Innocenzi, G. J. A. A. Soler-Illia, Chem. Mater. 2009, 21, 2763-2769.

[12] J. D. Bass, D. Grosso, C. Boissière, E. Belamie, T. Coradin, C. Sanchez, Chem. Mater. 2007, 19, 4349-4356.

[13] M. C. Fuertes, S. Colodrero, G. Lozano, A. R. González-Elipe, D. Grosso, C. Boissière, C. Sánchez, G. J. A. A. Soler-lllia, H. Míguez, J. Phys. Chem. C 2008, 112, 3157-3163.
[14] Y. Kim, S. H. Eom, J. Wang, D.-S. Lee, S. W. Suh, T. A. Steitz, Nature, 1995, 376, 612-616; measures along molecule maximum axes obtained with JMol, on the molecular structure file extracted from the RCSB Protein database, Taq DNA polymerase, file 1TAQ, available at http://nist.rcsb.org/pdb/explore/jmol.do?structureId=1TAQ, accessed Jan 13th 2010.

[15] Z. Bu, R. Biehl, M. Monkenbusch, D. Richter, D. J. E. Callaway, Proc. Natl. Acad. Sci. 2005, 102, 17646-17651.

[16] C. Boissière, D. Grosso, S. Lepoutre, L. Nicole, A. Brunet-Bruneau, C. Sanchez, Langmuir 2005, 21, 12362-12371.

[17] a) E. Topoglidis, T. Lutz, R. L. Willis, C. J. Barnett, A. E. G. Cass, J. R. Durrant, Faraday Discuss. 2000, 116, 35-46; b) E. Topoglidis, C. J. Campbell, A. E. G. Cass, J. R. Durrant, Langmuir. 2001, 17, 7899-7906; c) A. D. Weisz, A. E. Regazzoni, M. A. Blesa, Croat. Chem. Acta. 2007, 80, 325-332.

[18] a) R. Jenison, M. Rihanek, B. Polisky, Biosens. Bioelectron. 2001, 16, 757-763; b) E. T. Lagally, I. Medintz, R. A. Mathies, Anal. Chem. 2001, 73, 565-570.

[19] a) S. A. Deepak, K. R. Kottapalli, R. Rakwal, G. Oros, K. S. Rangappa, H. Iwahashi, Y. Masuo, G. K. Agrawal, Curr. Genom. 2007, 8, 234251; b) S. G. Houghton, F. R. Cockerill, Surgery 2006, 139, 1-5.

[20] a) M. U. Koop, A. J. Mello, A. Manz, Science 1998, 280, 10461048; b) C. Zhang, J. Xu, W. Ma, W. Zheng, Biotechnol. Adv. 2006, 24, 243-284; c) J. Pipper, Y. Zhang, P. Neuzil, T.-M. Hsieh, Angew. Chem. Int. Ed. 2008, 47, 3900-3904.

[21] a) H. Yan, Science 2004, 306, 2048-2049; b) C. Lin, H. Yan, Nat. Nanotechnol. 2009, 4, 211-212.

[22] W. Fontana, Science 2006, 314, 1554-1553.

Received: January 16, 2010

Revised: March 1, 2010

Published online: 